\title{
JM
}

Volume 7 No. 2 (Oktober 2019)

(C) The Author(s)

\section{PENGARUH IMT (INDEKS MASA TUBUH) TERHADAP TERJADINYA INFERTILITAS SEKUNDER PADA PERAWAT WANITA DI RSUD TAHUN 2017}

\section{EFFECT OF BMI (BODY MASS INDEX) ON THE OCCURRENCE OF SECONDARY INFERTILITY IN FEMALE NURSES IN HOSPITALYEARS 2017}

\author{
RENNY ADELIA TARIGAN, SUCI RIDMADHANTI \\ PROGRAM STUDI D-III KEBIDANAN STIKES MITRA BUNDA PERSADA BATAM \\ Email: renny.adelya27@gmail.com
}

\begin{abstract}
ABSTRAK
Obesitas berkaitan dengan tiga perubahan yang mengganggu ovulasi normal dan penurunan berat badan akan memperbaiki tiga keadaan tersebut : penurunan aromatisasi perifer dari androgen menjadi estrogen, penurunan kadar globulin pengikat hormone seks (sex hormone), hormone binding globulin (SHBG), menghasilkan peningkatan kadar estradiol dan testosterone bebas sehingga dapat mempengaruhi kesuburan. Tujuan penelitian ini melihata apakah ada pengaruh IMT terhadap terjadinya Infertilitas sekunder pada perawat wanita. Jenis penelitian yang digunakan dalam penelitian ini adalah kuantitatif dengan desain Cross Sectional, pengumpulan data Infertilitas sekunder dan IMT, dengan menggunakan kuesioner dan timbangan BB serta pengkur TB. Analisis data Bivariat dengan menggunakan Uji Chi - Square Hasil penelitian menunjukkan bahwa perawat wanita di RSUD Binjai dari 80 responden ada hubungan yang signifikansi antara IMT dengan terjadinya infertilitas sekunder dengan nilai $\mathrm{p}=0,008<0,05$ yang artinya ada hubungan yang signifikan antara IMT dengan terjadinya Infertilitas sekunder pada perawat wanita di ruangan rawat inap RSUD Djoelham Binjai. Nilai $\mathrm{RP}=6,750$ yang artinya perawat wanita yang memiliki IMT tidak ideal berisiko 6,750 lebih besar mengalami kejadian Infertilitas sekunder dibanding dengan pekerja perawat wanita yang memiliki IMT Ideal dengan 95\% CI = 1,433-31,797. Berdasarkan hasil penelitian, disarankan bahwa setiap wanita harus tetap di jaga kesehatan reproduksi seperti nutrisi dan aktifitas sehari - hari sehingga memiliki Indeks masa tubuh yang ideal.
\end{abstract}

Kata Kunci : Infertilitas Sekunder, IMT, 2017

\begin{abstract}
Obesity is associated with three changes that interfere with normal ovulation and weight loss will improve these three conditions: decreased peripheral aromatization from androgen into estrogen, decreased levels of sex hormone binding globulin (sex Hormone binding globulin (SHBG), resulting in increased levels of estradiol and free testosterone so that it can affect fertility. The purpose of this study saw whether there was a BMI influence on the occurrence of secondary infertility in female nurses. The type of research used in this study is quantitative with Cross Sectional design, the collection of secondary and IMT infertility data, using BB questionnaires and TB weighers. Analysis of bivariate data Using Test Chi - Square results showed that women nurses in Binjai HOSPITAL from 80 respondents had a significance
\end{abstract}


relationship between the IMT and the occurrence of secondary infertility with a value of $\mathrm{P}=$ $0,008<0.05$ which Meaning there is a significant relationship between the IMT and the occurrence of secondary infertility in female nurses in the inpatient room RSUD Djoelham Binjai. The value of $\mathrm{RP}=6.750$ which means women nurses who have a IMT not ideal at risk 6.750 are experiencing secondary incidence of infertility compared to female nurse workers who have an Ideal IMT with $95 \%$ CI $=1,433-31,797$. Based on the results of the study, it is recommended that every woman should keep reproductive health care such as nutrients and day-to-day activities so that it has an ideal body time index.

Keywords: secondary infertility, BMI, 2017

\section{PENDAHULUAN}

Kehadiran seorang anak merupakan faktor penting dalam sebuah keluarga. Itulah sebabnya, ketika menikah, sebagian besar pengantin baru sibuk mencari cara segera mendapatkan momongan namun saat ini wanita banyak mengalami gangguan pada reproduksi seperti infertilitas. Infertilitas adalah ketidakmampuan untuk mengandung sampai melahirkan bayi hidup setelah satu tahun melakukan hubungan seksual yang teratur dan tidak menggunakan alat kontrasepsi apapun/setelah memutuskan untuk mempunyai anak.

Infertilitas dapat di kelompokkan menjadi infertilitas primer dan sekunder. Infertilitas primer terjadi jika pasangan belum pernah mengalami kosepsi setelah $12-24$ bulan berhubungan tanpa kontrasepsi, sedangkan infertilitas sekunder terjadi jika pasangan sebelumnya pernah mengalami konsepsi atau kehamilan minimal satu kali. Infertilitas membutuhkan perhatian di seluruh dunia maupun di Indonesia, karena banyak pasangan infertil di Indonesia khususnya pada wanita yang pernah kawin tapi tidak memiliki anak (Rahyani, 2013).

Data infertilitas di seluruh dunia menurut Badan Kesehatan Dunia (World Health Organization, WHO) dan laporan lainnya, diperkirakan 8-12\% pasangan yang mengalami masalah infertilitas selama masa reproduktif mereka. Jika delapan persen dari gambaran global populasi maka sekitar 60-80 juta pasangan yang belum dikarunia anak. Diperkirakan muncul sekitar 2 juta pasangan infertil baru setiap tahun dan jumlah ini terus meningkat (Chandran 2013).

Menurut Evers pada penelitian Chandran (2013) memperkirakan $10-15 \%$ pasangan di negara- negara industri mengalami infertilitas. Tracey Bushnik dkk memperkirakan prevalensi infertilitas wanita di Kanada berada diantara angka 11,5\% $15,7 \%$. Negara- negara Afrika prevalensi infertilitas berada di angka 9\% di Gambia oleh Sudby dkk. Terdapat sekitar 11,8\% di Ghana dan diantara $20-30 \%$ di Nigeria.

Terdapat sedikit data mengenai infertilitas yang terjadi di Asia dan Amerika latin. Namun data dari WHO menyebutkan secara global angka kejadian yang dialami wanita pada masa reproduksi di negara Asia dan Amerika latin berada diantara angka 8- 12 $\%$ wanita. Angka infertilitas di Indonesia yang dikemukan oleh Sumapraja berkisar (12$15 \%) .13$ Banyaknya pasangan infertilitas di Indonesia dapat di perhitungkan dari banyaknya wanita yang pernah kawin dan tidak mempunyai anak yang masih hidup. Menurut sensus penduduk terdapat (12\%) baik di desa maupun di kota atau sekitar 3 juta pasangan infertil tersebar di seluruh Indonesia, dari Jumlah tersebut terdapat perempuan infertil $15 \%$ pada Usia $30-34,30$ $\%$ pada usia 35 - 39, dan $64 \%$ pada usia 40 44 tahun. Berdasarkan jenis infertilitas, Samiha dkk dalam penelitian Chandran (2013) melaporkan dari 215 pasangan yang infertil terdapat 172 kasus (80 \%) pasangan yang mengalami infertilitas primer dan 43 kasus $(20 \%)$ pasangan yang mengalami infertilitas sekunder. Mosher Secara global dapat disimpulkan penyebab terjadinya infertilitas diakibatkan dari faktor laki- laki 
sekitar 30\% meliputi kelainan pengeluaran sperma, penyempitan saluran mani karena infeksi bawaan, faktor immunologik/antibodi, antisperma, serta faktor gizi dan gangguan dari perempuan $30 \%$ yang mempunyai masalah pada vagina, serviks, uterus, kelainan pada tuba, ovarium dan pada peritoneum. gangguan dari keduanya $30 \%$ dan yang tidak di ketahui sekitar 10\%. melaporkan dari semua wanita yang mengalami infertilitas di Amerika Serikat, infertilitas primer terdapat $65 \%$ wanita dan infertilitas sekunder terdapat $35 \%$ wanita.

Menurut Rahyani (2013) di Indonesia diperkirakan sekitar $8-12 \%$ atau sekitar 50 - 80 juta pasangan mengalami infertilitas selama masa reproduksi. Infertilitas menyebabkan masalah dalam kehidupan pasangan tujuan dari perkawinan pada setiap pasangan adalah mendapatkan keturuna. Berdasarkan hasil penelitian di berbagai bnegara, konsepsi terjadi lebih dari $80 \%$ pasangan dalam kurun waktu 1 tahun. Sebanyak 25\% konsepsi terjadi dalam bulan pertama, 75\% konsepsi terjadi pada 9 bulan pertama, dan $90 \%$ konsepsi terjadi pada 18 bulan pertama.

Angka infertilitas Sekunder yang tinggi, maka harus diketahui apa saja yang dapat mempengaruhi keadaan infertilitas terutama pada wanita bekerja. Berbagai faktor dapat menyebabkan seorang wanita menjadi infertil. Penyebab seorang wanita infertilitas salah satunya adalah obesitas (Sarwono 2009),

Menurut WHO, pada tahun 2014 terdapat 600 juta orang usia dewasa mengalami obesitas. Di Indonesia sendiri kejadian obesitas pada kelompok perempuan dewasa tahun 2013 yaitu sebesar 32,9\% yang mengalami kenaikan sebanyak $18 \%$ dari tahun 2017. Obesitas tidak hanya dapat menyebabkan penyakit kronis tetapi perempuan obesitas ternyata beresiko mengalami gangguan reproduksi dan menyebabkan infertilitas atau tidak subur. (Etika M, 2016)

Data mengenai terjadinya infertilitas pada seorang wanita di Indonesia umumnya dan di kota Medan khususnya masih mulai meningkat. Sebagaimana yang telah dijelaskan d iatas bahwa terjadinya infertiltas berbeda di setiap negara dan daerah, karena di setiap Negara berbeda faktor penyebab tergantung letak geografis, sosial budaya, ekonomi, gaya hidup seperti berat badan, Umur, dan riwayat PMS.

Berdasarkan penelitian yang dilakukan oleh National Center for Health Statistics menunjukkan bahwa wanita subur berusia dibawah 25 tahun memiliki kemungkinan hamil $96 \%$ dalam setahun, usia 25 - 34 tahun menurun menjadi $86 \%$ dan $78 \%$ pada usia 35 - 44 tahun. Gaya hidup dan faktor lingkungan dapat mempengaruhi fertilitas dan harus mempertimbangkan karena hampir $62 \%$ wanita Amerika kelebihan berat badan dan lainnya $33 \%$ obesitas. Kelebihan berat badan di defenisikan dengan Indeks masa tubuh (BMI) lebih besar dari 25 dan yang besar dari 30 disebut obesitas. Abnormalitas dari sekresi GnRH dan gonadotropin relative sering pada berat badan lebih, obesitas dan yang berat badan kurang (BMI kurang dari 17).

Orang yang mengalami obesitas, biasanya cenderung mengkonsumsi makanan dengan kalori, gula, dan lemak yang tinggi. Ketika tubuh mengkonsumsi terlalu banyak lemak maka akan muncul hormone leptin.Semakin tinggi kadar leptin menjadikan leptin resisten sehingga akan mengalami gangguan leftin dan dapat mempengaruhi ketidakseimbangan kadar hormone seksual seperti luteinizing hormone dan estradiol yang merupakan hormone kesuburan wanita. Dengan megetahui data-data ini diharapkan pencegahan, penanganan dan pelayanan bagi kasus - kasus infertilitas lebih dapat ditingkatkan dan dapat ditangani lebih komprehensip. (Etika M, 2016)

\section{METODE PENELITIAN}

Jenis penelitian ini adalah observasional analitik dengan rancangan penelitian cross sectional.Penelitian ini dilakukan pada bulan Januari 2017 - April 2017 Populasi penelitian ini adalah seluruh perawat wanita di ruang rawat inap di RSUD 
Dr. R.M Djoelham Binjai dengan 9 ruangan, ruang perawatan bedah 20 (2 ruangan) orang, ruangan perawatan anak 25 orang (2 ruagan), ruang perawatan kebidanan (2 ruangan) 15 orang dan penyakit dalam (3 ruangan yaitu Interna laki - laki, perempuan dan isolasi) 40 orang total populasi sebanyak 100 orang. Pengambilan sampel pada penelitian ini di lakukan dengan menggunakan teknik purposive sampling. yaitu teknik dengan tujuan atau pertimbangan tertentu yang memenuhi kriteria inklusi sebagai berikut : jenis kelamin wanita, lama bekerja 2 (dua tahun), lama menikah 2 tahun atau lebih, tergolong usia produktif (20-35 tahun), yang termasuk pada kriteria tersebut adalah dari ruangan bedah 22 orang, ruangan anak 12 orang, ruangan kebidanan 14 orang, dan ruangan penyakit dalam 32 orang, total sampel sebanyak 80 orang.

Penelitian ini menggunakan data primer dan data sekunder. Data primer diperoleh dengan cara: Melakukan pengukuran terhadap stress kerja dengan menggunkan kuesioner stress kerja yang telah di uji Validitas dan Reliabilitas di RSU Sembiring Delitua. Untuk melihat perawat wanita yang mengalami Infertilitas sekunder atau tidak dengan menggunakan wawancara dan memberikan pertanyaan terbuka. Defenisi operasional IMT Berat badan perawat saat penelitian yang akan di hitung menggunakan rumus IMT. Untuk membuktikan ada atau tidaknya pengaruh antara dua variabel tersebut, dilakukan uji statistik Chi-Square dengan derajat kepercayaan $95 \%$ dengan $\mathrm{p}<0.05$. Melalui perhitungan uji Chi-Square di tarik suatu kesimpulan, bila $\mathrm{p}<\alpha \quad(0,05)$ maka ada hubungan bermakna antara variabel dependen dengan variabel indenpenden dan bila $p>\alpha$ berarti tidak ada hubungan bermakna antara variabel dependen dengan variabel independen.

\section{HASIL PENELITIAN}

\section{A. IMT pada Perawat Wanita}

Perawat wanita yang di RSUD
Djoelham Binjai di peroleh bahwa mayoritas memiliki IMT tidak ideal diperoleh sebanyak 51 orang $(63,8 \%)$ dan yang memiliki IMT Ideal 29 orang $(36,3 \%)$.

Tabel 1. Distribusi Frekuensi IMT pada perawat wanita Tahun 2017

\begin{tabular}{ccc}
\hline Stress kerja & Jumlah (n) & Persentasi (\%) \\
\hline Indeks Masa & & \\
Tubuh & 51 & 63,8 \\
Tidak Ideal & 29 & 36,3 \\
Ideal & & \\
\hline Total & 80 & 100 \\
\hline
\end{tabular}

\section{B. Infertilitas Sekunder Perawat Wanita}

Perawat wanita yang di RSUD Djoelham Binjai di peroleh bahwa mayoritas tidak mengalami Infertilitas diperoleh sebanyak 61 orang $(76,3 \%)$ dan yang mengalami Infdertilitas sekunder 19 orang $(23,8 \%)$.

Tabel 2. Distribusi Frekuensi terjadinya infertilitas sekunder pada perawat wanita tahun 2017

\begin{tabular}{ccc}
\hline $\begin{array}{c}\text { Infertilitas } \\
\text { sekunder }\end{array}$ & Jumlah (n) & Percentage (\%) \\
\hline Ya & 19 & 23,8 \\
\hline Tidak & 61 & 76,3 \\
\hline Jumlah (n) & 80 & $100.00 \%$ \\
\hline
\end{tabular}

\section{Hubungan Stress Kerja Terhadap terjadinya Infertilitas Sekunder pada perawat wanita}

Berdasarkan tabulasi silang antara IMT dengan terjadinya Infertilitas sekunder pada perawat wanita menunjukkan bahwa dari 51 orang yang tidak ideal terdapat 17 orang $(33,3 \%)$ mengalami infertilitas sekunder dan sebanyak 34 orang $(66,7 \%)$ yang tidak mengalami infertilitas sekunder. Pada 29 orang yang memiliki IMT ideal terdapat sebanyak 2 orang $(6,9 \%)$ yang mengalami Infertilitas sekunder dan 27 orang $(93,1 \%)$ tidak mengalami infertilitas sekunder. Hasil uji bivariat menunjukkan bahwa nilai $\mathrm{p}=0,008<0,05$ yang artinya ada hubungan 
yang signifikan antara IMT dengan terjadinya Infertilitas sekunder pada perawat wanita di ruangan rawat inap RSUD Djoelham Binjai. Nilai $R P=6,750$ yang arinya perawat wanita yang memiliki IMT tidak ideal berisiko 6,750 lebih besar mengalami kejadian Infertilitas sekunder dibanding dengan pekerja perawat wanita yang memiliki IMT Ideal dengan 95\% $\mathrm{CI}=1,433-31,797$.

Tabel 3. Hubungan IMT Dengan Terjadinya Infertilitas Sekunder Pada Perawat Wanita tahun 2017

\begin{tabular}{|c|c|c|c|c|c|c|c|}
\hline \multirow{3}{*}{ IMT } & \multicolumn{2}{|c|}{$\begin{array}{c}\text { Infertilitas } \\
\text { sekunder }\end{array}$} & \multirow{2}{*}{\multicolumn{2}{|c|}{ Jumlah }} & \multirow{3}{*}{$p}$. & \multirow{3}{*}{ RP } & \multirow{3}{*}{$95 \% \mathrm{CI}$} \\
\hline & Ya & Tidak & & & & & \\
\hline & n $\%$ & n $\%$ & $\mathrm{n}$ & $\%$ & & & \\
\hline $\begin{array}{l}\text { Tidak } \\
\text { Ideal }\end{array}$ & 1733,3 & $34 \quad 66,7$ & 51 & $\begin{array}{c}100, \\
0\end{array}$ & 0,00 & & 1,$433 ; 3$ \\
\hline Ideal & $\begin{array}{ll}2 & 6,9\end{array}$ & 2793,1 & 29 & $\begin{array}{c}100, \\
0\end{array}$ & 8 & & 797 \\
\hline
\end{tabular}

\section{PEMBAHASAN}

A. Pengaruh IMT Terhadap Terjadinya Infertilitas Sekunder Pada Perawat wanita di Ruangan Rawat Inap RSUD Djoelham Binjai Tahun 2017

Variabel karakteristik responden Berat badan secara statistik menunjukkan bahwa kemungkinan berat badan yang tidak ideal mempenagruhi kesuburan pada wanita . hal ini sejalan dengan penelitian(Kasdu 2008). Gaya hidup dan faktor lingkungan dapat mempengaruhi fertilitas dan harus mempertimbangkan karena hampir $62 \%$ wanita Amerika kelebihan berat badan dan lainnya $33 \%$ obesitas. Kelebihan berat badan di defenisikan dengan Indeks masa tubuh (BMI) lebih besar dari 25 dan yang besar dari 30 disebut obesitas. Abnormalitas dari sekresi $\mathrm{GnRH}$ dan gonadotropin relative sering pada berat badan lebih, obesitas dan yang berat badan kurang (BMI kurang dari 17).

Hubungan antara BMI dan kesuburan pada pria belum teliti secara rinci. Frekuensi obesitas pada wanita dengan anovulasi dan suatu ovarium polikistik telah dilaporkan adalah berkisar dari $35 \%$ hingga $60 \%$. Obesitas berkaitan dengan tiga perubahan yang mengganggu ovulasi normal dan penurunan berat badan akan memperbaiki tiga keadaan tersebut : penurunan aromatisasi perifer dari androgen menjadi estrogen, penurunan kadar globulin pengikat hormone seks (sex hormone), hormone binding globulin (SHBG), menghasilkan peningkatan kadar estradiol dan testosterone bebas sehingga dapat mempengaruhi kesuburan.

Penghitungan indeks massa tubuh (Body Mass Index (BMI)) dihitung dari tinggi dan berat badan $(\mathrm{kg} / \mathrm{m} 2)$ - kisaran normal BMI adalah $20-25 \mathrm{~kg} / \mathrm{m} 2$. Penampilan/ rupa pasien secara keseluruhan dapat memberikan petunjuk mengenai penyakit sistemik ataupun masalah endokrin .Wanita dengan siklus menstruasi yang tidak teratur dan tampilan fisik obesitas mungkin saja berhubungan dengan diagnosis SOPK. Pada umumnya wanita dengan tampilan overweight atau obesitas mengalami kelainan berupa resistensi insulin atau bahkan sindroma metabolik.

Hasil uji bivariat menunjukkan bahwa nilai $\mathrm{p}=0,008<0,05$ yang artinya ada hubungan yang signifikan antara IMT dengan terjadinya Infertilitas sekunder pada perawat wanita di ruangan rawat inap RSUD Djoelham Binjai. Nilai $R P=6,750$ yang arinya perawat wanita yang memiliki IMT tidak ideal berisiko 6,750 lebih besar mengalami kejadian Infertilitas sekunder dibanding dengan pekerja perawat wanita yang memiliki IMT Ideal dengan 95\% $\mathrm{CI}=1,433-31,797$.

\section{KESIMPULAN}

Didapatkan IMT yang tidak ideal dan kejadian Infertilitas sekunder pada perawat wanita di ruangan Rawat Inap RSUD Djoelham Binjai. Perawat wanita yang memiliki IMT tidak ideal beresiko terjadinya Infertilitas sekunder. Hubungan antara BMI dan kesuburan pada pria belum teliti secara rinci. Frekuensi obesitas pada wanita dengan anovulasi dan suatu ovarium polikistik telah dilaporkan adalah berkisar dari 35\% hingga 
$60 \%$. Obesitas berkaitan dengan tiga perubahan yang mengganggu ovulasi normal dan penurunan berat badan akan memperbaiki tiga keadaan tersebut : penurunan aromatisasi perifer dari androgen menjadi estrogen, penurunan kadar globulin pengikat hormone seks (sex hormone), hormone binding globulin (SHBG), menghasilkan peningkatan kadar estradiol dan testosterone bebas sehingga dapat mempengaruhi kesuburan.

\section{SARAN}

Perlu adanya peringatan kepada setiap wanita yang sudah menikah untuk tetap menjaga indek masa tubuh yang ideal agar menjaga nutrisi dan lakukan olahraga atau aktifitas yang membakar lemak.

\section{DAFTAR PUSTAKA}

Adriani, $\quad \mathrm{M}(2012)$. Pengantar Gizi Masyarakat. Jakarta: Kencana Prenada Media

Aisah, S. 2010. Kecemasan Pada Pasangan Menikah Yang Belum Memiliki Keturunan. Universitas Gunadarma

Aisyaroh, N. (2012). Kesehatan Reproduksi Remaja. Jurnal Majalah Ilmiah Sultan Agung di terbitkan oleh Unissula.www.unnissula.ac.id

Anastasya, O. 2014.Faktor - Faktor yang Mempengaruhi Infertilitas pada Wanita di Klinik Fertilitas Endokrinologi Reproduksi, Program Stiudi Pendidikan Dokter Fakultas Kedokteran Unsri

Al, L. E.T. (2002). Associations of body mass index and obesity with physical activity, food choices, alcohol intake, and smoking in the. Am J Cin Nutr

Arikunto S. Prosedur Penelitian Suatu Pendekatan Praktik. Jakarta.Rineke Cipta. 2006

Arisman. (2010). Gizi Dalam Daur Kehidupan: Buku Ajar Imu Gizi, Jakarta: EGC

Arief M., (2008). Pengantar Metodologi Penelitian untuk imlu kesehatan. Surakarta: LPP UNS dan UNS Press.
Kasdu, Dini, 2011. Kiat Sukses Pasangan Memperoleh Keturunan, Jakarta : Puspa Swara

Mumtaz et al. Reproductive Health 2013, 10:3 http://www.reproductive-healthjournal.com/content $/ 10 / 1 / 3$

Rasmun, 2008, Stress, Koping dan Adaptasi. Jakarta : Sagung Seto

Ryo S. Gobel 2014. Faktor - Faktor Yang Berhubungan Dengan Stres Kerja Pada Perawat di Ruang ICU dan UGD RSUD Datoe Binangkang Kabupaten Bolang Mongondow.

Suharsini, A, 2012 Prosedur Penelitian Suatu Pendekatan Praktik, Jakarta : Rineka Cipta

Suma'mur, 2009. Higene Perusahaan dan Kesehatan Kerja, Jakarta : Gunung Agung

Tarwaka. 2010 Ergonomi Industri. Dasar Dasar Pengetahuan Ergonomi dan Aplikasi di Tempat Kerja, Surakarta

Wade, Carole, Tavris, Carol. 2007. Psikologi, Jakarta : Penerbit Erlangga. 